\title{
Reflexões sobre o ensino híbrido como uma inovação disruptiva para a educação
}

\author{
Reflections on hybrid teaching as a disruptive innova- \\ tion for education
}

\section{Reflexiones sobre la enseñanza híbrida como una in- novación disruptiva para la educación}

\section{DÉBORA SCHUCK KNAUTH}

Universidade Feevale

(Blended: Usando a inovação disruptiva para aprimorar a educação. Michael B. Horn; Heather Staker. USA. [tradução: Maria Cristina Gularte Monteiro] - Porto Alegre: Penso, 2015. p. 292. ISBN 978-85-8429-044-4).

A obra aqui analisada, originalmente publicada sob o título "Blended: Using disruptive innovation to improve schools", apresenta um largo estudo e levantamento de dados de instituições educacionais que vem utilizando o ensino híbrido para aprimorar a educação. O livro traz problematizações e possibilidades através de modelos pedagógicos que utilizam o ensino híbrido. A obra original é dividida em quatro partes: 1) entendimento; 2) mobilização; 3) planejamento; e 4) implementação. Ainda, diversos materiais de apoio, como vídeos, tabelas, esquemas e resumos auxiliam na compreensão da teoria e da prática por trás das inovações na educação. O presente texto, buscou desenvolver uma resenha crítica do livro em questão.

A aprendizagem de alunos é foco de interesse em estudos e pesquisas há muitas décadas. Entretanto, a educação do modelo industrial (i.e. ensino tradicional), que vinha sendo desenvolvida e estudada até então, não atende mais as demandas expostas pelo novo perfil de aluno. Isso ocorre porque a demanda por educação cresceu, o perfil dos alunos mudou e o avanço tecnológico impôs novos desafios para alunos e educadores. Hoje sabemos que cada aluno tem aptidões diferentes, capacidade e tempo de aprendizagem distintos. Além disso, estão conectados a uma rede de informações em tempo real, o que não acontecia há alguns anos atrás. Compreender estas relações é importante para começar a remodelar o ensino escolar, para que este se torne mais eficiente no processo de aprendizagem dos alunos.

A aprendizagem centrada no aluno é uma abordagem que auxilia na mudança do ensino e no rompimento de paradigmas na educação, onde professores vinham se comportando como transmissores de conhecimento e alunos como receptores de informações. Esta aprendizagem centrada no aluno conduz a um ensino personalizado e uma aprendizagem baseada na competência, diferente da baseada em tempo (onde a unidade acadêmica determina quanto 
tempo é necessário para cada conteúdo). Isso evita principalmente grandes lacunas de conhecimento para os alunos. O desejo de personalização do ensino, juntamente com o desejo de acesso e de controle de custos são citados por líderes de diversas instituições como os principais porquês de mudar o ensino tradicional.

Baseada na aprendizagem centrada no aluno, uma alternativa ao ensino tradicional é o ensino híbrido. Para ser híbrido, o ensino deve: a) em parte, ocorrer por ensino on-line, onde o aluno aprende controlando seu tempo, lugar, conteúdo e ritmo de aprendizagem; b) em parte, em um local físico supervisionado, longe de casa; c) ser uma experiência de aprendizagem integrada. Para evitar a falta de integração entre conteúdo on-line e escolar físico, muitos programas usam sistemas de dados computadorizados.

Infelizmente, o ensino híbrido é facilmente confundido com programas e dispositivos de computadores, ou com o uso de tecnologias na educação (edtech). Entretanto, o ensino híbrido é uma abordagem de grande potencial que conta com diversos modelos de aprendizagem, onde os estudantes desenvolvem a capacidade de progresso e autonomia da aprendizagem. Neste sentido, o ensino on-line, que é o pilar central do ensino híbrido, é importante para personalizar a aprendizagem, uma vez que pagar por educação individualizada seria inviável.

A teoria dos híbridos traz que, híbridos podem surgir em qualquer tipo de serviço ou setor, quando produtos ou serviços tradicionais são combinados a alguma inovação. No começo, obviamente, os híbridos não são excelentes, mas com o tempo eles se aperfeiçoam e tendem a substituir a versão tradicional. Híbridos podem ser classificados em inovações sustentadas, quando trazem a versão tradicional junto com a inovação ou tecnologia, ou inovações disruptivas, quando apresentam apenas a nova versão/tecnologia. Na educação, as inovações sustentadas podem ser mais difíceis de operar porque demandam expertise de ambas as partes, ou seja, do ensino tradicional e dos dispositivos digitais, sistemas e operações. Diferente das inovações sustentadas, as inovações disruptivas trazem grandes mudanças e novos desafios em uma perspectiva de educação. Estas inovações são recentes, mas vêm mostrando resultados surpreendentes em muitas instituições, especialmente nos Estados Unidos. Estudos trazem que a inovação disruptiva pode levar mais tempo do que o necessário para se estabelecer, uma vez que vem sendo implementada em espaços físicos de escolas tradicionais, as quais, da maneira como estão organizadas hoje, não são os locais ideais para esta nova proposta de ensino. Entretanto, é importante esclarecer que propostas de ensino baseadas em inovações disruptivas irão mudar as escolas em nível de sala de aula, e não em nível de instituição. As escolas continuarão existindo, contudo, provavelmente apresentarão arquiteturas físicas diferentes e novas dinâmicas de ensino e aprendizagem.

Entre as vantagens da mudança na educação, tanto por abordagens baseadas em inovações sustentadas como disruptivas, está a possibilidade das escolas focarem seus esforços em atividades como oferta de disciplinas extras e eletivas, atividades de artes, teatro, esporte, projetos, entre outras que são fundamentais para o desenvolvimento dos alunos quanto cidadãos. Uma vez que as novas abordagens de ensino ajudam os alunos a saber, a escola pode ajudar os alunos a fazer e ser. Além disso, as escolas podem focar em questões sociais, o que 
beneficia não só os alunos, mas as famílias e a comunidade. Esse papel da escola se torna ainda mais importante em locais de vulnerabilidade social.

Problemas escolares, como disparidade na aprendizagem entre alunos, desistências escolares, notas baixas, carência de disciplinas eletivas ou atividades extracurriculares são o ponto de entrada para experimentar a aprendizagem centrada no aluno sem incorrer em resistência por parte do sistema já estabelecido. Ainda, para evitar tentativas de implementação mal sucedidas, os líderes e equipe escolar devem discutir os objetivos SMART (Specific, Measurable, Attributable, Realist, Time). Ou seja, o objetivo que se pretende atingir visa melhorar qual área específica? Ele quantifica ou possui um indicador de progresso? Quem será o responsável pela equipe, pela mudança, pelas avaliações, etc? Os resultados podem ser alcançados de forma realista, dada a disponibilidade de recursos? E em quanto tempo os resultados podem ser alcançados? Depois disso, se faz necessário preparar uma equipe correspondente com os objetivos e magnitude das mudanças na instituição.

Quando optado pela mudança de ensino e discutido os objetivos, um dos maiores erros é esperar que professores consigam implementar, por si só, um modelo de ensino disruptivo. Eles não são capazes de fazer isso sem a ajuda de líderes, diretores, coordenadores e equipes específicas que tenham autonomia na escola e comunidade. Contar com professores motivados é extremamente importante para o sucesso de novos modelos na educação. Professores precisam estar engajados às novas propostas e seguros do trabalho que irão desenvolver. Eles não podem sentirem-se substituídos pelos novos modelos ou plataformas de ensino on-line. Pelo contrário, as ferramentas, plataformas e sistemas vêm para facilitar e ampliar a possibilidade de trabalho dos professores. Além disso, podem ajudar no reconhecimento e promoção do trabalho dos professores. Entretanto, estes profissionais precisam estar familiarizados as tecnologias propostas e motivados a realizar a mudança junto a equipe pedagógica.

Para o sucesso de novos modelos, além de uma equipe qualificada e motivada, é necessário se colocar no lugar dos alunos para entender suas dificuldades e anseios. Alunos querem ter sucesso e sentir que estão tendo progresso. Eles querem se divertir com os amigos, ter experiências positivas. A escola deve ser um local para estas experiências. Dessa forma, o ensino deve oportunizar aos alunos a terem um plano de aprendizagem pessoal, um feedback constante de seus desempenhos, experiências coletivas e orientação por um mentor.

Um último ponto importante que deve ser considerado pelas equipes é o espaço físico e a dinâmica que ele proporciona. A arquitetura das escolas do modelo industrial limita a personalização e flexibilidade do ensino. Muitas escolas nos Estados Unidos estão adaptando seus prédios para locais mais amplos e integrados. O tipo de arquitetura da instituição dependerá do objetivo que se pretende atingir e os métodos que serão aplicados. Contudo, é importante considerar mudanças na estrutura física da escola quando se opta por modelos disruptivos, porque estes exigem uma grande dinâmica e integração do trabalho. Existem modelos que vêm sendo utilizados e se encaixam em muitos objetivos que as instituições buscam. Abaixo, segue a lista de sete modelos de ensino híbrido, trazidos e discutidos no livro aqui analisado, sendo os três primeiros baseados em inovações sustentadas e os demais baseados em inovações mais disruptivas: 
1) Rotação por estações: modelo onde os alunos alternam tempo de estudo entre salas de aula com atividades diferentes. Isso oportuniza um trabalho dinâmico entre orientações mais individualizadas, projetos e discussões em grupos de tamanhos variados. Este tipo de modelo vem sendo utilizado por professores há décadas, mas a novidade hoje é a inclusão do ensino online dentro do circuito de rotação.

2) Laboratório rotacional: alunos aprendem parte dos conteúdos em um laboratório de informática, supervisionados por monitores, e parte em sala de aula tradicional, com professores. A proporção de tempo seria de aproximadamente $25 \%$ do tempo em laboratório e $75 \%$ em sala de aula. A grande vantagem deste modelo é liberar tempo para os professores se dedicarem a outras tarefas, projetos e demandas do ensino. O desafio é manter integrado o ensino on-line com o ensino em sala de aula.

3) Sala de aula invertida: alunos têm aulas ou palestras on-line, em casa, de forma independente, e o tempo em sala de aula é reservado para "lição de casa", ou seja, para esclarecimento de dúvidas, participação ativa e atividades práticas. A vantagem deste modelo é a autonomia que os alunos adquirem, podendo avançar ou retroceder nos conteúdos de maneira independente e usando o tempo com os professores para atividades que auxiliem de fato na aprendizagem.

4) Rotação individual: alunos rotam entre atividades, mas seus cronogramas são personalizados por softwares ou por um professor. O aluno pode fornecer avaliações diárias para o software que analisa os resultados e combina as melhores lições para o dia seguinte. A vantagem é a personalização do ensino e economia de custos a longo prazo, entretanto a implementação deste modelo requer um investimento financeiro inicial alto em equipamentos e sistemas.

5) Modelo Flex: modelo no qual o ensino on-line é o pilar principal de aprendizagem. As atividades são prioritariamente em um espaço físico escolar. Há orientação por parte dos professores e estes estão no mesmo espaço que os alunos, mas os alunos têm um cronograma personalizado entre as modalidades de aprendizagem e bastante autonomia. A diferença é que neste caso, escolas iniciam com ensino on-line e adicionam apoio físico quando necessário. $O$ envolvimento do professor com cada aluno ou grupo/projeto dependerá das demandas de cada situação.

6) Modelo À La Carte: uma forma bastante comum de ensino híbrido é este, no qual o aluno inclui ao seu ensino tradicional qualquer disciplina ou curso on-line de seu interesse. A diferença neste caso é que a modalidade on-line não conta com um componente presencial e o professor ou tutor é também on-line. É um modelo que possibilita uma gama de oportunidades para a formação independente dos alunos.

7) Modelo Virtual Enriquecido: neste modelo os alunos participam de aulas presenciais obrigatórias em alguns dias da semana, e o restante do trabalho é realizado de maneira on-line em casa. A frequência dos encontros presenciais pode variar conforma as necessidades dos alunos. A diferença neste modelo é que as experiências presenciais não acontecem todos os dias, mas é um componente de ensino obrigatório. 
Conhecer os modelos de ensino híbrido que estão dando certo é importante para professores, coordenadores e líderes de instituições acadêmicas. Este assusto é emergente e tende a crescer muito nos próximos anos. O ensino híbrido poderá ajudar em muitas demandas das escolas, como carência de corpo docente, instalações físicas insuficientes, redução de custos, evasão escolar, notas baixas, entre outras. Os modelos descritos aqui trazem oportunidades para estas demandas, porque podem tornar o tempo presencial dos professores mais produtivo, os espaços escolares melhor aproveitados (e.g. através da rotação presencial de alunos, formação de grupos), e tornar o ensino mais atrativo e motivador, auxiliando principalmente na aprendizagem personalizada dos alunos. Entretanto, a realidade de cada escola, de cada comunidade, geralmente é muito distinta. Assim, muitas instituições vêm desenvolvendo modelos de ensino múltiplos, para criar um programa personalizado que atenda aos objetivos específicos.

O ensino híbrido implica mais do que vincular tecnologias a salas de aula, ele envolve planejamento profundo do modelo pedagógico, reflexão das demandas dos alunos e integração de todas as partes da escola. A integração das partes é essencial para um bom resultado, mas pode se tornar um desafio em alguns modelos. Atenção a questões como esta são mais importantes do que questões especificamente tecnológicas em uma perspectiva de ensino híbrido. Com o constante avanço tecnológico, tentar oferecer sempre o mais recente é um exercício de futilidade, uma vez que o equipamento/software escolhido logo estará desatualizado. Depois de escolhida e adaptada, a tecnologia não precisa, nem deve, ser substituída a cada lançamento ou nova proposta.

Grandes avanços para a melhoria da educação vêm acontecendo, especialmente em países desenvolvidos. Trazer estas experiências para locais com históricos e características diferentes, como o Brasil, é desafiador. Neste caso, torna-se importante considerar as circunstâncias locais e adaptar os modelos e tecnologias para alcançar os objetivos com sucesso. A inovação é um processo, leva tempo e é construída a partir de tentativas e erros. O mais importante é uma ação bem planejada e a vontade de fazer melhor a cada novo desafio. Os resultados surgirão e o trabalho poderá ser aperfeiçoado. Certamente, aqueles que começarem agora a experimentar e a vivenciar as inovações estarão em vantagem quando a demanda por educação centrada no aluno se expandir.

\section{Referência}

Horn, M. B.; Staker, H. Blended: Usando a inovação disruptiva para aprimorar a educação. [tradução: Maria Cristina Gularte Monteiro] - Porto Alegre: Penso, 2015. p. 292. ISBN 978-858429-044-4

\section{Agradecimento}

Débora Schuck Knauth agradece à professora Dra. Patrícia Brandalise Scherer Bassani pela revisão desta resenha e pelas orientações de estudos. 


\section{Débora Schuck Knauth}

Programa de Pós-graduação em Diversidade Cultural e Inclusão Escolar, grupo de pesquisa Informática na Educação - Universidade FEEVALE, Novo Hamburgo - Brasil. deboraknauth@hotmail.com 